\title{
ATP2B1 rs2681472 and STK39 rs35929607 polymorphisms and risk of Hypertension in Iranian Population
}

\author{
Javad Jamshidi ${ }^{1}$, Ali Asnaashari ${ }^{2}$, Reza Alipoor ${ }^{3}$, Sina Mohammadi², Sara Roostaei ${ }^{2}$, \\ Mohammad Mahdi Samadian ${ }^{4}$, Saiedeh Honarmand Aliabadi ${ }^{2}$, Ehsan Bahramali*1,5
}

\section{Abstract}

Background: $A T P 2 B 1$ and STK39 have been introduced as essential hypertension candidate genes. The association of these genes' variations have not been studied in Iranian population yet. Here we aimed to investigate the association of $A T P 2 B 1 \mathrm{rs} 2681472$ and STK39 rs35929607 polymorphisms with the risk of hypertension in an Iranian population.

Methods: We included 400 individuals in our case-control study: 200 cases with essential hypertension and 200 healthy sex and age matched controls. All subjects were genotyped for rs2681472 and rs35929607 using a PCR-RFLP method. Genotype and allele frequencies were compared between the two groups using chi-squared test. The association was further assessed under log-additive, dominant and recessive genetic models.

Results: There was no association between rs2681472 and rs35929607 polymorphisms and risk of essential hypertension in our population $(\mathrm{p}>0.05)$. There was also no association between the studied polymorphisms and hypertension under different genetic models.

Conclusion: Our study indicated that rs2681472 of ATP2B1 and rs35929607 of STK39 may not have a significant effect on the risk of essential hypertension in Iranian population. More studies are still needed to validate our results.

Keywords: Essential hypertension, ATP2B1, STK39, Polymorphism, Association study

Copyright@ Iran University of Medical Sciences

Cite this article as: Jamshidi J, Asnaashari A, Alipoor R, Mohammadi S, Roostaei S, Samadian MM, Honarmand Aliabadi S, Bahramali E. ATP2B1 rs2681472 and STK39 rs35929607 polymorphisms and risk of Hypertension in Iranian Population. Med J Islam Repub Iran. $2018(20$ Feb);32:14. https://doi.org/10.14196/mjiri.32.14

\section{Introduction}

Blood pressure (BP) is a quantitative and highly variable trait in humans (1). There is a strong positive association between BP and cardiovascular disorders (CVD) such as stroke, heart failure and myocardial infraction (2). High $\mathrm{BP}$ or hypertension is a predominant risk factor for CVD which is preventable. It is estimated that about $31 \%$ of world's adults had hypertension in 2010, although this is a mean and hypertension prevalence can be very variable among different countries and races (3). The agestandardized prevalence of hypertension have been reported to be about $41.8 \%$ in a large cohort of Iranian population (4). Essential or primary hypertension is defined as

Corresponding author: Dr Ehsan Bahramali, ebahramali@fums.ac.ir

1. Noncommunicable Diseases Research Center, Fasa University of Medical Sciences, Fasa, Iran.

2. Student Research Committee, Fasa University of Medical Sciences, Fasa, Iran

3. Department of Biochemistry, Hormozgan University of Medical Sciences, Bandar Abbas, Iran.

4. Department of Medical Genetics, Mashhad University of Medical Sciences, Mashhad, Iran.

5. Department of Cardiology, Fasa University of Medical Sciences, Fasa, Iran. high BP with the absent of secondary causes such as renal failure, pheochromocytoma, aldosteronism, or other causes which accounts for $95 \%$ of all cases (5). Both environmental and genetic factors are involved in the development of essential hypertension. The heritability of BP is estimated to be between $30-60 \%$ which shows a significant contribution of genetics to this trait (6), and because of that many researches have been dedicated to find genetic components of hypertension.

ATPase plasma membrane $\mathrm{Ca} 2+$ transporting 1 (ATP2B1) plays a critical role in intracellular calcium homeostasis (7). This gene was shown to be related to sys-

$\uparrow$ What is "already known" in this topic:

There is evidence that ATP2B1 and STK39 polymorphism are associated with the risk of essential hypertension. The majority of evidences are from European and East Asian populations and the results are not all consistent. There was no data available considering the relation of these genes with essential hypertension in Iranian population.

$\rightarrow$ What this article adds:

Our data indicated that variants in ATP2B1 and STK39 genes probably do not have a significant effect on the risk of essential hypertension in Iranian population. 
Table 1. Demographic and laboratory data of case and control groups

\begin{tabular}{lccc}
\hline Variable & Case $(\mathrm{N}=200)$ & Control $(\mathrm{N}=200)$ & p-value \\
\hline Age $(\mathrm{year})$ & $57.22 \pm 9.34$ & $56.59 \pm 12.98$ & 0.57 \\
BMI $\left(\mathrm{Kg} / \mathrm{m}^{2}\right)$ & $24.67 \pm 4.17$ & $24.51 \pm 3.66$ & 0.68 \\
Sex $(\mathrm{F} / \mathrm{M})$ & $112 / 88$ & $119 / 81$ & 0.41 \\
Smoking $(\%)$ & $22(11)$ & $14(7)$ & 0.16 \\
DM $(\%)$ & $15(7)$ & $8(4)$ & 0.13 \\
SBP $(\mathrm{mmHg})$ & $140.59 \pm 23.42$ & $113.22 \pm 9.96$ & $<0.0001$ \\
DBP (mmHg) & $84.86 \pm 11.89$ & $72.12 \pm 8.55$ & $<0.0001$ \\
HB $(\mathrm{g} / \mathrm{dL})$ & $12.81 \pm 1.78$ & $12.49 \pm 2.07$ & 0.10 \\
Cr $(\mathrm{mg} / \mathrm{dL})$ & $1.14 \pm 1.38$ & $1.15 \pm 0.32$ & 0.69 \\
FBS $(\mathrm{mg} / \mathrm{dL})$ & $125.15 \pm 62.68$ & $120.52 \pm 58.41$ & 0.44 \\
TG (mg/dL) & $128.50 \pm 80.60$ & $118.66 \pm 25.84$ & 0.10 \\
LDL (mg/dL0 & $106.57 \pm 45.12$ & $100.53 \pm 47.23$ & 0.19 \\
HDL (mg/dL) & $43.95 \pm 8.43$ & $45.12 \pm 5.87$ & 0.10 \\
\hline BMI: body mass index, DM: diabetes mellitus, SBP: systolic blood pressure, DBP: diastolic blood pressure, HB: hemoglobin, Cr: creatinine, FBS:
\end{tabular}

tolic blood pressure (SBP), diastolic blood pressure (DBP), and hypertension in a genome wide association study (8). It has also been shown that variations of $A T P 2 B 1$ are associated with hypertension in East Asians (9) and European populations (10). STK39 (serine/threonine kinase 39) is a sterile 20-like-related prolinealanine-rich kinase that keep the salt-water homeostasis by mediating the phosphorylation of numerous cationchloride-coupled cotransporters (11). The possible link between STK39 and hypertension was first reported in a genome wide association (GWA) study in 2009 (12). After that, replication studies were performed in different ethnic groups, but the results are not consistent (13).

To the best of our knowledge, there is no study reporting the association of $A T P 2 B 1$ or STK 39 variations with susceptibility to hypertension in Iranian population. Here we selected a SNP in each of these genes (ATP2B1 rs2681472 and STK39 rs35929607) which were previously studied in other populations. We investigated in our study the association of rs2681472 and rs35929607 with essential hypertension through a case-control study in an Iranian population.

\section{Methods \\ Study population}

Our research was a case-control study comprising 200 patients with essential hypertension as case group and 200 healthy individuals as control group. Both case and control groups were randomly selected from individuals referred to clinics of Fasa University Hospital. Diagnosis of essential hypertension was made upon JNC-8 criteria of BP greater than 140/90 on two separate measurements, at least 15 minutes apart, in the absence of secondary causes. Individuals in control group were free of hypertension without any previous history and their BP was measured before taking the blood sample as well. In addition to SBP and DBP, a set of demographic (Age, BMI, Sex, Smoking and Diabetes Mellitus (DM) status) and general laboratory tests (HB, Cr, FBS, TG, LDL and HDL) were measured in all samples, which is reported in Table 1 . Individuals with history of other CVD including coronary artery disease, systolic heart failure, cardiomyopathies and significant valvular diseases were excluded from the study. Individuals in case and control groups were all ethnically Iranian. Informed consent was taken from all participants and the study was approved by the ethic committee of Fasa University of Medical Sciences (IR.FUMS.REC.1394.8).

\section{DNA extraction and genotyping}

About $3 \mathrm{ml}$ of peripheral blood was taken from every participant and DNA was extracted using a standard salting out method. PCR-RFLP method was used for genotyping of rs2681472 and rs35929607. The PCRs were performed using $20 \mu \mathrm{l}$ of reaction mixture containing $0.4 \mu \mathrm{M}$ of each primer, $200 \mathrm{mM}$ of dNTPs, $2 \mathrm{mM} \mathrm{MgCl}_{2}$ and 1 unit of Taq DNA polymerase (Amplicon, Denmark). The products were digested using appropriate restriction enzymes in $37{ }^{\circ} \mathrm{C}$ for 3 hours. The details of PCR programs and digestions are described in Table 2. The digested PCR products were separated using 3\% agarose gel electrophoresis staining with Power load (Kawsar Biotech, Iran).

\section{Statistical Analysis}

Quantitative variables are presented as mean \pm standard deviation, and difference between groups was determined using student's t-test. The Hardy-Weinberg equilibrium was estimated in the population (whole study population and also control group) using chi-squared test. Chi-square test was also used to compare the genotype and allele frequencies between the case and the control groups. Addi-

Table 2. The Primer sequences and digestion conditions for studied polymorphisms

\begin{tabular}{|c|c|c|c|c|c|c|c|}
\hline \multirow[t]{2}{*}{ Polymorphisms } & \multirow[t]{2}{*}{ Primer sequences $(5 \rightarrow 3)$} & \multicolumn{3}{|c|}{ PCR conditions $\left({ }^{\circ} \mathrm{C} / \mathrm{s}\right)$} & \multirow{2}{*}{$\begin{array}{l}\text { Restriction } \\
\text { enzyme } \\
\text { digestion }\end{array}$} & \multirow[t]{2}{*}{ Alleles } & \multirow{2}{*}{$\begin{array}{c}\text { DNA } \\
\text { fragment } \\
\text { size (bp) }\end{array}$} \\
\hline & & Denature & Annealing & Extension & & & \\
\hline \multirow[t]{2}{*}{ rs2681472 } & F: TCTGAGGATGTGGCATTTGA & $95 / 35$ & $58 / 30$ & $72 / 30$ & PvuII at $37 \mathrm{C}$ & $\mathrm{T}$ & 203 \\
\hline & R: CCCAGTAAGGCCAGAGATCA & & & & for 3 hours & $\mathrm{C}$ & $141+62$ \\
\hline \multirow[t]{2}{*}{ rs 35929607} & F: AACACTCTCACAAGAAGAGATCCCAGTG & $95 / 35$ & $61 / 40$ & $72 / 45$ & MspI at & A & 349 \\
\hline & R: CTCCCAGGTCGTTTTCAAACAAAAATAA & & & & $\begin{array}{c}37^{\circ} \mathrm{C} \text { for } 3 \\
\text { hours }\end{array}$ & G & $201+148$ \\
\hline
\end{tabular}


tionally, the association of genotypes with essential hypertension was assessed under log-additive, dominant and recessive genetic models using SNPassoc package of $\mathrm{R}$ program (14). All statistical analysis was carried out using $\mathrm{R}$ version 3.2.3.

\section{Results}

Four hundred subjects, 200 with hypertension (mean age \pm standard deviation: 57.22 \pm 9.34 years) and 200 healthy sex and age matched controls (mean age \pm standard deviation: $56.59 \pm 12.98$ years) were included in this study. Except for SBP and DPB (which was expected) group analysis revealed no significant difference in demographic and laboratory data of the case and the control groups (Table 1).

The studied population was in Hardy-Weinberg equilibrium for both SNPs $(\mathrm{p}>0.05)$. The distribution of genotype and allele frequencies were not different between the case and the control groups for any of rs2681472 and rs35929607 polymorphisms (Table 3). There was also no association between essential hypertension and studied polymorphisms when analyzing under different genetic models (Table 4).

\section{Discussion}

In the current study, we demonstrated that there is no association between essential hypertension and ATP2B1 rs2681472 and $S T K 39$ rs35929607 in a cohort of Iranian population. The genotypes were evenly distributed among patients with hypertension and control group and still allele frequencies were not different.

$A T P 2 B 1$ have been reported as a candidate gene for blood pressure in several GWA studies in people of European, and east Asian origin (Japanese, Chinese and Koreans) $(8,15-17)$. The gene is involved in calcium homeostasis which is critical for normal vascular contraction (18), the function that could be related to BP regulation. $A T P 2 B 1$ variants have been widely studied in east Asian populations through replication studies, and the results are in favor of $A T P 2 B 1$ involvement in hypertension in these populations (19). Despite this, there are only a few studies reporting the association of $A T P 2 B 1$ variations and risk of hypertension in other populations. Nonetheless, ATP2B1 was not associated with blood pressure in an African American cohort (20), which is consistent with our study findings. Based on our findings we assume that $A T P 2 B 1$ is not a significant determinant in the pathophysiology of hypertension in Iranian population or there may be a protective gene functioning in this population.

Since the introduction of STK39 as a candidate gene for essential hypertension in a GWAS, there has been interest toward (8) delineation of its function in the pathophysiology of hypertension. Results of the replication studies were also mixed and some support the association of STK39 variations with hypertension, like those being conducted in Belgian (rs3754777) (21), Chinese (rs6433027 and rs3754777) (11) and Swedish populations (rs35929607) (22) while others failed to prove any association, such as studies in Chinese (rs6749447, rs3754777, rs35929607, rs4667569, rs4977950) (23), Korean (rs3754777 and rs6749447) (24) and British Caucasian populations(rs6749447, rs3754777, rs35929607) (25). Our study is in agreement with the latter studies and supports a lack of association in Iranian population. Along with the studies with conflicting results in Chinese population (11, $23)$, two meta-analyses about STK39 and risk of hypertension are also demonstrative of inconclusive findings (13, 26).

It seems that despite many studies that have investigated the association of $A T P 2 B 1$ and STK39 gene variations with essential hypertension, the results are still inconsistent. It could be concluded that these variations only have significant effect in specific populations and ethnic groups which can be explained by the different genetic backgrounds in various ethnicities. Furthermore, environmental exposures and life styles as hypertension risk factors have different implications and significance among various populations. Similarly, the observed discrepancy regarding this polymorphisms and hypertension in different populations can be attributed to gene-environment interactions which itself can be secondary to the modifier

Table 3. Genotype and allele frequencies in case and control groups

\begin{tabular}{|c|c|c|c|c|c|c|c|c|c|c|}
\hline \multirow{2}{*}{ Gene (SNP) } & \multirow[t]{2}{*}{ Subjects (n) } & \multicolumn{3}{|c|}{ Genotype frequencies (\%) } & \multirow[t]{2}{*}{$\mathrm{p}$} & \multicolumn{2}{|c|}{ Allele frequencies $(\%)$} & \multirow[t]{2}{*}{$\mathrm{p}$} & \multirow[t]{2}{*}{ OR } & \multirow[t]{2}{*}{$95 \% \mathrm{CI}$} \\
\hline & & TT & $\mathrm{TC}$ & $\mathrm{CC}$ & & $\mathrm{T}$ & $\mathrm{C}$ & & & \\
\hline $\begin{array}{l}\text { ATP2B1 } \\
\text { (rs2681472) }\end{array}$ & $\begin{array}{c}\text { Case }(200) \\
\text { Control }(200) \\
\text { Total }(400)\end{array}$ & $\begin{array}{c}86(43) \\
86(43) \\
172(43) \\
\text { AA }\end{array}$ & $\begin{array}{c}91(45.5) \\
92(46) \\
183(45.7) \\
\text { AG }\end{array}$ & $\begin{array}{c}23(11.5) \\
22(11) \\
45(11.3) \\
\text { GG }\end{array}$ & 0.99 & $\begin{array}{c}263(66) \\
264(66) \\
527(65.8) \\
A\end{array}$ & $\begin{array}{c}137(34) \\
136(34) \\
273(34.2) \\
G\end{array}$ & 1 & 1.01 & $0.75-1.35$ \\
\hline $\begin{array}{l}\text { STK39 } \\
\text { (rs35929607) }\end{array}$ & $\begin{array}{c}\text { Case }(200) \\
\text { Control }(200) \\
\text { Total }(400)\end{array}$ & $\begin{array}{l}118(59) \\
112(56) \\
230(58)\end{array}$ & $\begin{array}{c}70(35) \\
79(39.5) \\
149(37)\end{array}$ & $\begin{array}{l}12(6) \\
9(4.5) \\
21(5)\end{array}$ & 0.56 & $\begin{array}{c}306(76.5) \\
303(76) \\
609(76)\end{array}$ & $\begin{array}{c}94(23.5) \\
97(24) \\
191(24)\end{array}$ & $\begin{array}{c}0 . \\
80\end{array}$ & 0.95 & $0.69-1.32$ \\
\hline
\end{tabular}

Table 4. Analysis of Genotype distribution between the case and the control groups

\begin{tabular}{|c|c|c|c|c|}
\hline Gene (SNP) & & $\begin{array}{c}\text { log-Additive } \\
(\mathrm{TT}=0, \mathrm{TC}=1, \mathrm{CC}=2)\end{array}$ & $\begin{array}{c}\text { Recessive } \\
\text { (TT and TC vs CC) }\end{array}$ & $\begin{array}{c}\text { Dominant } \\
(\mathrm{TC} \text { and } \mathrm{CC} \text { vs. TT) }\end{array}$ \\
\hline \multirow{4}{*}{ ATP2B1 (rs2681472) } & $\mathrm{p}$ & 0.98 & 0.87 & 1 \\
\hline & OR & 1.05 & 1.05 & 1 \\
\hline & $95 \% \mathrm{CI}$ & $0.54-2.02$ & $0.57-1.96$ & $0.67-1.49$ \\
\hline & & log-Additive $(\mathrm{AA}=0, \mathrm{AG}=1, \mathrm{GG}=2)$ & Recessive (AA and AG vs GG) & Dominant (GG and AG vs. AA) \\
\hline \multirow{3}{*}{ STK39 (rs35929607) } & $\mathrm{p}$ & 0.80 & 0.50 & 0.54 \\
\hline & OR & 0.96 & 1.35 & 0.88 \\
\hline & $95 \% \mathrm{CI}$ & $0.69-1.33$ & $0.59-1.32$ & $059-1.32$ \\
\hline
\end{tabular}


effects like what has been proposed as the mechanism for the attenuation or blunting of the genetic factors. For instance, it has been demonstrated that smoking is a significant risk factor for the association of rs3754777 of STK39 with hypertension (13). Therefore, investigations in subgroups and taking multiple exposures into account as well would yield in a better understanding to the role of these polymorphisms in the susceptibility to hypertension.

Being a multifactorial disease with a handful of environmental, genetic and behavioral contributors, hypertension must be viewed as a complex outcome. Excluding secondary hypertension, the etiology of essential hypertension cannot be explained by a single determinant like a mutation. There are plenty of modifier and protective traits as well, which mostly are related to life style and genetic factors $(27,28)$. Polymorphisms that are proposed as candidates for hypertension development in GWASs, then must be studied separately in different populations with special considerations about the confounding effects of diet, life style and behavioral factors. A longitudinal cohort study of non-hypertensive population is the best fit for such association studies and can clearly account for major confounders. This study must be interpreted with its limitations including restricted number of cases, possible confounding factors and limited number of studied SNPs. A larger cohort of seemingly healthy individuals with long enough follow ups to get the hypertension as an outcome, will properly address the causality of these polymorphisms in hypertension.

\section{Conclusion}

Our study indicates that rs2681472 and rs35929607 and probably ATP2B1 and STK39 genes do not have a significant effect on susceptibility to hypertension in Iranian population. Functional in vitro studies may help to clarify the exact effect of these variations in essential hypertension. More studies are still required to validate our study results.

\section{Acknowledgements}

We would like to thank all people who helped us with collecting the samples and the laboratory works. This study was founded by Fasa University of Medical Sciences (Grant number: 93198 and 93191).

\section{Conflict of Interests}

The authors declare that they have no competing interests.

\section{References}

1. Stephan D, Gaertner S, Cordeanu EM. A critical appraisal of the guidelines from France, the UK, Europe and the USA for the management of hypertension in adults. Arch Cardiovasc Dis. 2015;108(8-9):453-9.

2. Ettehad D, Emdin CA, Kiran A, Anderson SG, Callender T, Emberson J, et al. Blood pressure lowering for prevention of cardiovascular disease and death: a systematic review and metaanalysis. Lancet. 2016;387(10022):957-67.

3. Mills KT, Bundy JD, Kelly TN, Reed JE, Kearney PM, Reynolds K, et al. Global Disparities of Hypertension Prevalence and Control: A Systematic Analysis of Population-Based Studies From 90 Countries. Circulation. 2016;134(6):441-50.
4. Malekzadeh MM, Etemadi A, Kamangar F, Khademi H, Golozar A, Islami F, et al. Prevalence, awareness and risk factors of hypertension in a large cohort of Iranian adult population. J Hypertens. 2013;31(7):1364-71; discussion 71.

5. Carretero OA, Oparil S. Essential hypertension. Part I: definition and etiology. Circulation. 2000;101(3):329-35.

6. Zhao Q, Kelly TN, Li C, He J. Progress and future aspects in genetics of human hypertension. Curr Hypertens Rep. 2013;15(6):676-86.

7. Little R, Cartwright EJ, Neyses L, Austin C. Plasma membrane calcium ATPases (PMCAs) as potential targets for the treatment of essential hypertension. Pharmacol Ther. 2016;159:23-34.

8. Levy D, Ehret GB, Rice K, Verwoert GC, Launer LJ, Dehghan A, et al. Genome-wide association study of blood pressure and hypertension. Nat Genet. 2009;41(6):677-87.

9. Kato N, Takeuchi F, Tabara Y, Kelly TN, Go MJ, Sim X, et al. Metaanalysis of genome-wide association studies identifies common variants associated with blood pressure variation in east Asians. Nat Genet. 2011;43(6):531-8.

10. Newton-Cheh C, Johnson T, Gateva V, Tobin MD, Bochud M, Coin $\mathrm{L}$, et al. Genome-wide association study identifies eight loci associated with blood pressure. Nat Genet. 2009;41(6):666-76.

11. Chen LY, Zhao WH, Tian W, Guo J, Jiang F, Jin LJ, et al. STK39 is an independent risk factor for male hypertension in Han Chinese. J Biol Chem. 2012;154(2):122-7.

12. Wang Y, O'Connell JR, McArdle PF, Wade JB, Dorff SE, Shah SJ, et al. From the Cover: Whole-genome association study identifies STK39 as a hypertension susceptibility gene. Proc Natl Acad Sci U S A. 2009;106(1):226-31.

13. Yang H, Ye L, Wang Q, Cai D, Chen Q, Pan H, et al. A metaanalytical assessment of STK39 three well-defined polymorphisms in susceptibility to hypertension. Sci Rep. 2016;6:25290.

14. Gonzalez JR, Armengol L, Sole X, Guino E, Mercader JM, Estivill $\mathrm{X}$, et al. SNPassoc: an $\mathrm{R}$ package to perform whole genome association studies. Bioinformatics. 2007;23(5):644-5.

15. Takeuchi F, Isono M, Katsuya T, Yamamoto K, Yokota M, Sugiyama $\mathrm{T}$, et al. Blood pressure and hypertension are associated with 7 loci in the Japanese population. Circulation. 2010;121(21):2302-9.

16. Lu X, Wang L, Lin X, Huang J, Charles Gu C, He M, et al. Genomewide association study in Chinese identifies novel loci for blood pressure and hypertension. Hum Mol Genet. 2015;24(3):865-74.

17. Kelly TN, Takeuchi F, Tabara Y, Edwards TL, Kim YJ, Chen P, et al. Genome-wide association study meta-analysis reveals transethnic replication of mean arterial and pulse pressure loci. Hypertension. 2013;62(5):853-9.

18. Hirawa N, Fujiwara A, Umemura S. ATP2B1 and blood pressure: from associations to pathophysiology. Curr Opin Nephrol Hypertens. 2013;22(2):177-84.

19. Xi B, Tang W, Wang Q. Polymorphism near the ATP2B1 gene is associated with hypertension risk in East Asians: a meta-analysis involving 15909 cases and 18529 controls. Blood Press. 2012;21(2):134-8.

20. Fox ER, Young JH, Li Y, Dreisbach AW, Keating BJ, Musani SK, et al. Association of genetic variation with systolic and diastolic blood pressure among African Americans: the Candidate Gene Association Resource study. Hum Mol Genet. 2011;20(11):2273-84

21. Persu A, Evenepoel L, Jin Y, Mendola A, Ngueta G, Yang WY, et al. STK39 and WNK1 Are Potential Hypertension Susceptibility Genes in the BELHYPGEN Cohort. Medicine. 2016;95(15):e2968.

22. Fava C, Danese E, Montagnana M, Sjogren M, Almgren P, Engstrom G, et al. Serine/threonine kinase 39 is a candidate gene for primary hypertension especially in women: results from two cohort studies in Swedes. J Hypertens. 2011;29(3):484-91.

23. Xu J, Ji LD, Zhang LN, Dong CZ, Fei LJ, Hua S, et al. Lack of association between STK39 and hypertension in the Chinese population. J Hum Hypertens. 2013;27(5):294-7.

24. Shin DJ, Lee SH, Park S, Jang Y. Association between Serine/Threonine Kinase 39 Gene Polymorphism, Hypertension, and Other Cardiovascular Risk Factors in Koreans. Korean Circ J. 2013;43(1):13-22.

25. Cunnington MS, Kay C, Avery PJ, Mayosi BM, Koref MS, Keavney B. STK39 polymorphisms and blood pressure: an association study in British Caucasians and assessment of cis-acting influences on gene expression. BMC Med Genet. 2009;10:135.

26. Xi B, Chen M, Chandak GR, Shen Y, Yan L, He J, et al. STK39 
polymorphism is associated with essential hypertension: a systematic review and meta-analysis. PloS one. 2013;8(3):e59584.

27. Bahramali E, Rajabi M, Jamshidi J, Mousavi SM, Zarghami M, Manafi A, et al. Association of ACE gene D polymorphism with left ventricular hypertrophy in patients with diastolic heart failure: a casecontrol study. BMJ open. 2016;6(2):e010282.

28. Bahramali E, Firouzabadi N, Rajabi M, Manafi A, Zarghami M, Mousavi SM, et al. Association of renin-angiotensin-aldosterone system gene polymorphisms with left ventricular hypertrophy in patients with heart failure with preserved ejection fraction: A casecontrol study. Clin Exp Hypertens. 2017;39(4):371-6. 